\title{
Evaluation of Structural Anomalies of Kidney and Urinary Tract in Children with Down Syndrome
}

\author{
Mayank Jain • Ankur Singh • Mukta Mantan • \\ Seema Kapoor
}

Received: 29 May 2013 / Accepted: 29 August 2013 / Published online: 21 September 2013

(C) Dr. K C Chaudhuri Foundation 2013

To the Editor: Down syndrome (DS) is the most common chromosomal abnormality with a prevalence of 1.72 per 1,000 total births [1]. The congenital anomalies in Down syndrome can involve any system with varying degree of severity and thus, requires active referral on part of clinician to improve the standard of care in such group of DS patients. At present, screening for renal and urinary tract anomalies is not standard care during the initial evaluation of newborns with DS. To answer this question, we undertook the present study to look for structural anomalies of kidney and urinary tract in cases with Down syndrome. Forty children with chromosomal diagnosis of Down syndrome were enroled in the study over a period of two months. The age group of patients was birth to $18 \mathrm{y}$. All patients were screened for any urinary complaints according to predesigned performa. Subjects were further evaluated by ultrasonography of kidney, ureter, and bladder region (KUB) for any structural anomalies. Further DTPA scan, micturating cystourethrography $(\mathrm{MCU})$ were performed in cases where it was indicated. Frequency of urinary symptoms in decreasing order were dysuria (11/40), increased frequency (7/40), incontinence (6/40), hesitancy $(6 / 40)$, poor urinary stream $(3 / 40)$, hematuria $(2 / 40)$ and post micturition dribbling (2/40). Incidence of Renal and Urinary Tract Anomalies (RUTA) were hydronephrosis (20\%), renal parenchymal thickening, dilatation of ureter, renal hypoplasia, vesico-

\section{Jain}

MBBS student, MAMC Associated Lok Nayak Hospital,

New Delhi 110002, India

\section{A. Singh $\cdot$ M. Mantan $\cdot$ S. Kapoor $(\square)$}

Department of Pediatrics, MAMC Associated Lok Nayak Hospital,

New Delhi 110002, India

e-mail: drseemakapoor@gmail.com ureteric reflux, pelvi-ureteric junction obstruction, renal calculi and neurogenic bladder as seen in previous studies [2, 3].

Unlike previous studies, we found a high prevalence of RUTAs in DS pediatric population, supporting our hypothesis $[4,5]$. The higher incidence of RUTA in our study may be attributed to small sample size and limited screening of DS patients brought to health facility. Another limitation of our study is that we did not include the derangements in kidney function test and pathological findings like renal hypoplasia, immature glomeruli and tubular dilation. Despite these limitations, our study points to significant abnormality in KUB region of these patients. This needs to be further authenticated by a large population based study so that clinical guidelines are formulated for better care of DS patients in resource poor countries like ours.

Conflict of Interest None.

Role of Funding Source STS awarded to Dr Mayank Jain from the ICMR. He was also awarded for the oral presentation at Medsicon.

\section{References}

1. Irving C, Basu A, Richmond S, Burn J, Wren C. Twenty-year trends in prevalence and survival of Down syndrome. Eur J Hum Genet. 2008; 16:1336- 40 .

2. Ahmed S. Vesico-ureteric reflux in Down's syndrome: Poor prognosis. Aust N Z J Surg. 1990;60:113-6.

3. MMercer ES, Broecker B, Smith EA, Kirsch AJ, Scherz HC, A Massad C. Urological manifestations of Down syndrome. J Urol. 2004;171:1250-3.

4. Kupferman JC, Stewart CL, Kaskel FJ, Katz SP, Fine RN. Chronic peritoneal dialysis in a child with Down syndrome. Pediatr Nephrol. 2008;28:558-9.

5. Kupferman JC, Druschel CM, Kupchik GS. Increased prevalence of renal and urinary tract anomalies in children with Down syndrome. Pediatrics. 2009;124:e615-21. 